\title{
Review Article \\ The Dormancy Marker DRM1/ARP Associated with Dormancy but a Broader Role In Planta
}

\author{
Georgina M. Rae, ${ }^{1,2}$ Karine David, ${ }^{2}$ and Marion Wood ${ }^{1}$ \\ ${ }^{1}$ The New Zealand Institute for Plant \& Food Research Limited, Mt Albert, Private Bag 92169, Auckland Mail Centre, \\ Auckland 1142, New Zealand \\ ${ }^{2}$ Plant Molecular Sciences, School of Biological Sciences, University of Auckland, Private Bag 92019, Auckland Mail Centre, \\ Auckland 1142, New Zealand
}

Correspondence should be addressed to Georgina M. Rae; georgina.rae@plantandfood.co.nz

Received 28 February 2013; Revised 15 May 2013; Accepted 16 May 2013

Academic Editor: M. Pisano

Copyright (C) 2013 Georgina M. Rae et al. This is an open access article distributed under the Creative Commons Attribution License, which permits unrestricted use, distribution, and reproduction in any medium, provided the original work is properly cited.

\begin{abstract}
Plants must carefully regulate their development in order to survive a wide range of conditions. Of particular importance to this is dormancy release, deciding when to grow and when not to, given these varying conditions. In order to better understand the growth release mechanism of dormant tissue at the molecular and physiological levels, molecular markers can be used. One gene family that has a long association with dormancy, which is routinely used as a marker for dormancy release, is DRM1/ARP (dormancyassociated gene-1/auxin-repressed protein). This plant-specific gene family has high sequence identity at the protein level throughout several plant species, but its function in planta remains undetermined. This review brings together and critically analyzes findings on the DRM1/ARP family from a number of species. We focus on the relevance of this gene as a molecular marker for dormancy, raising questions of what its role might actually be in the plant.
\end{abstract}

\section{Introduction}

Plants are sessile; therefore, a number of mechanisms are elegantly managed in the plant to ensure its survival and optimisation in its given setting. Integral to this is the temporal and spatial determination of growth in relation to the surroundings. This growth may be vegetative, such as axillary budbreak and branch development, or floral, including flower and fruit development. To achieve this, cell division, cell elongation, or a combination of the two has been shown to play a pivotal role in plant growth regulation.

Dormancy is a means of ensuring a plant's long-term survival and is defined as the "transitory delay of visible growth that occurs in plant meristematic tissues" [1]. An example of this occurs in perennials over winter. When temperatures are low and daylight hours are limited, plants protect themselves by ceasing growth, waiting for the more favourable conditions of spring in which they focus their resources on growing and reproducing. As such, the key decisions around when to release dormant tissue from dormancy (dormancy release/shoot outgrowth/shoot branching) are an important mechanism for plant biologists to understand.

Both perennial and annual plants (e.g., Arabidopsis) also undergo a type of dormancy known as apical dominance or paradormancy, where endogenous signals/hormones from the apical bud are received by lower axillary meristems, preventing their bud outgrowth. This phenomenon was first described in 1934 [2], when it was shown that axillary buds of decapitated plants were released from dormancy due to a lack of auxin flow down the stem. Since then, the interactions between auxin and other hormones including cytokinin (growth promoting) and strigolactone (branching inhibition) have been studied in-depth in order to better understand the complex cross-talk which is controlling this process [3].

Mutant lines exhibiting hyperbranching phenotypes have been integral to these dormancy release studies. These included characterisation of the $M A X / C C D / R M S$ pathway involved in strigolactone biosynthesis and perception (reviewed by Seto et al. [4]); and more recently, additional hyperbranching mutants, the bud-specific dormancy release 
signal integrator $b r c 1 / t b l 1$, have also been studied in order elucidate alternate pathways involved in this critical process. These studies relied heavily on the use of a genetic marker for dormancy status-dormancy-associated gene 1 (DRM1)/auxin repressed protein $(A R P)$. This review will present literature associated with $D R M 1 / A R P$ from a number of species (summarised in Table 1) and will discuss the relevance of using $D R M 1 / A R P$ as a molecular marker for dormant tissues.

\section{DRM1/ARP and Dormancy}

The first studied member of the DRM1/ARP gene family whose transcript expression was linked with dormancy physiology, PsDRM (dormancy-associated gene)-1, was isolated from differential display performed with cDNA libraries from dormant and growing axillary buds of pea. To consider the relationship between expression of this gene and axillary bud dormancy, Stafstrom et al. [5] decapitated Alaska pea plants. By removing the apical buds of the pea plants, the bud can be released from paradormancy (apical dominance), allowing outgrowth of the axillary buds (Figure 1). PsDRM1 expression was analysed by northern blot in the bud at various time points after decapitation and revealed that upon release of dormancy, PsDRM1 levels decreased 20-fold with a concomitant increase in the expression of the cell cycle marker gene, PsRPL27 [5].

Two homologues to PsDRM1 have been identified in Arabidopsis: AtDRM1 (At1g28330) and AtDRM2 (At2g33830; formally known as AtDRM1-homologue). As in pea, a decapitation was conducted in Arabidopsis showing that AtDRM1 and AtDRM2 expression levels decreased with the release of paradormancy [6]. Subsequent expression levels increased from $24 \mathrm{~h}$ after decapitation, due to a putative apical dominance from the primary axillary outgrowth, leading to paradormancy in the lower buds.

Dormancy release experiments performed with AdDRM1, the DRM1/ARP homologue in Actinidia deliciosa (kiwifruit), using hydrogen cyanamide (commercially available as HiCane) as a dormancy release agent show the same expression profiles [7]. Treatment with hydrogen cyanamide was used to release the apical buds from endodormancy (compared with decapitation initiating release of apical buds from paradormancy in pea and Arabidopsis). Upon release of bud dormancy, the characteristic decrease in AdDRM1 expression was seen. In the same experiment, the expression of AdCDKB (cyclin-dependant protein kinase B), a marker for growth from kiwifruit, was assessed. Cyclin-dependent kinases (CDKs) are known to be involved in the reinitiation of cell cycle progression through the $\mathrm{G}_{1}-\mathrm{S}$ phase transition [8]. As $A d D R M 1$ levels decrease, $A d C D K B$ expression increases [7].

Further evidence of an association of DRM1/ARP transcripts with periods of dormancy is seen in PsARP (Paeonia suffruticosa auxin-repressed protein), a gene identified as being associated with the release of dormant buds of tree peony. PsARP showed a sharp increase prior to bud break and then dropped to low levels as the buds grew [9].

In most cases, increases in DRM1/ARP expression are associated with reduced branching phenotypes: $p h y b[10]$, tin
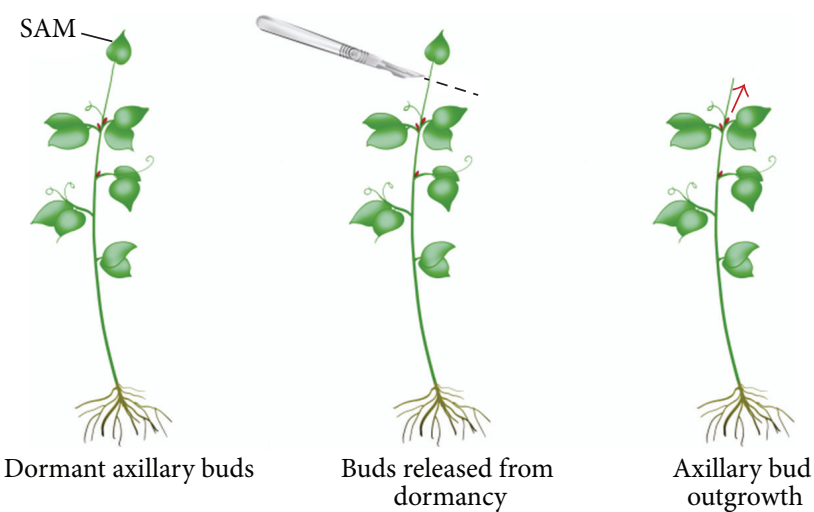

FIgURE 1: The "decapitation experiment" used by Stafstrom et al. [5] to induce release of dormancy.

[11], and CHR12 OX [12]; and decreases in DRM1/ARP expression are associated with increased branching phenotypes: axr1-12 [13], max2 [13], and chr12 [12] (Table 2). However, $D R M 1 / A R P$ has also been used as a marker for dormancy in Arabidopsis in studies of Teosinte branched 1-like or branched 1 (TBL1 or BRC1) [13] with less dependability. Results showed that a reduction in mRNA expression of DRM1/ARP was not required for bud outgrowth leading to the conclusion at the time that $D R M 1 / A R P$ was probably acting upstream of $T B L 1$ [13]. Alternatively, DRM1/ARP could be acting independently of TBL1. In the same study, there was no change in DRM1/ARP transcript levels in hyperbranching 35S:YUCCA where you may anticipate a reduction in expression, providing further evidence that $D R M 1 / A R P$ may not be playing a role specifically in holding back bud outgrowth.

These findings weaken the argument for DRM1/ARP as a molecular marker for dormancy in axillary buds. Alternatively, these data suggest that DRMI/ARP is playing a role as an integrator only under a subset of specific dormancyrelated conditions.

\section{The $D R M 1 / A R P$ Protein Family}

Database searches show that the DRM1/ARP family is unique to plants, with homologues found in both monocotyledons and Dicotyledons [25]. Multiple protein sequence alignments show high conservation of the DRM1/ARP protein product, with two domains clearly identifiable at the aminoterminus and at the carboxy-terminus [7, 25]. This high conservation across species, and indeed monocotyledons and Dicotyledons, suggests a potential importance of the action of this protein in the normal development and physiology of plants. Moreover, the protein product is conserved in its size, with all 11 species analysed by Park and Han [25] between 11 and $14 \mathrm{kDa}$ (between 109 and 126 amino acid residues). GFP fusion constructs of EuNOD-ARP1 (EuNODARP1; Elaeagnus umbellata nodule auxin-repressed protein gene 1), a DRM1/ARP homologue in the ornamental shrub E. umbellata (Japanese silverberry, Autumn-Olive), as well as GFP fusion constructs of Brassica rapa DRM1 and ARP1 suggest that it is cytosol-localised $[16,18]$. However, in silico 


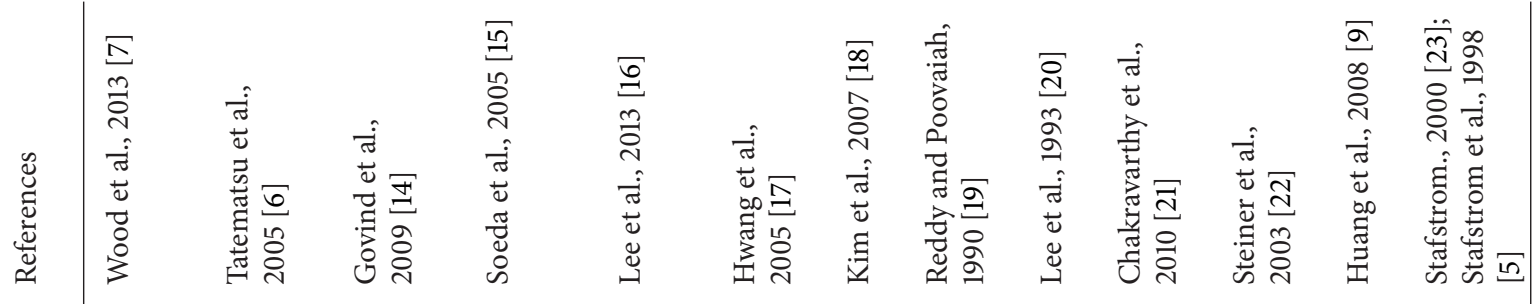

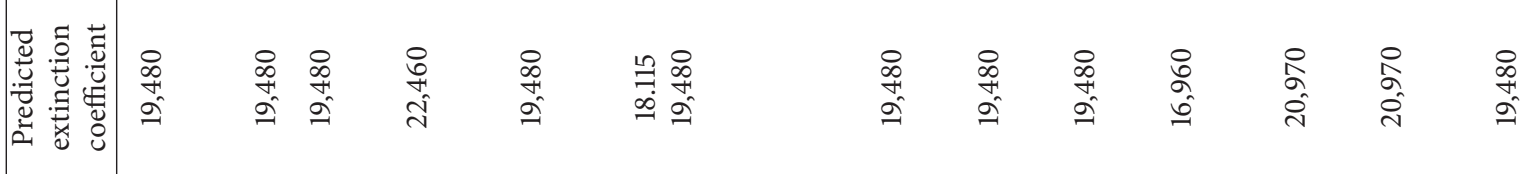

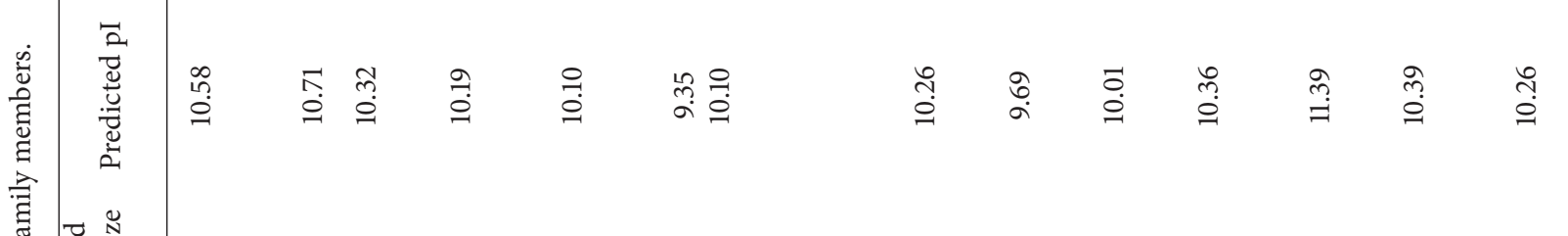

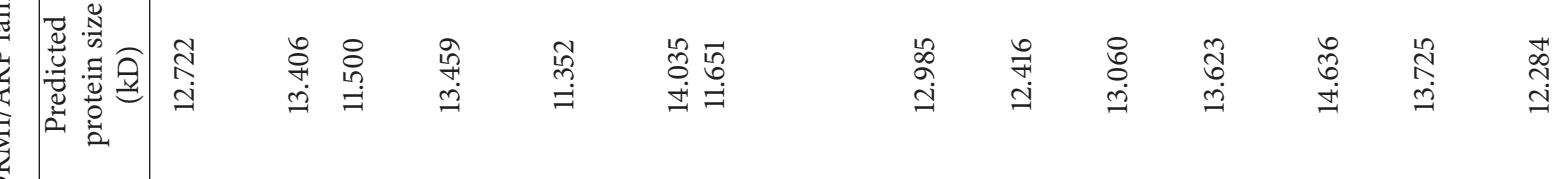

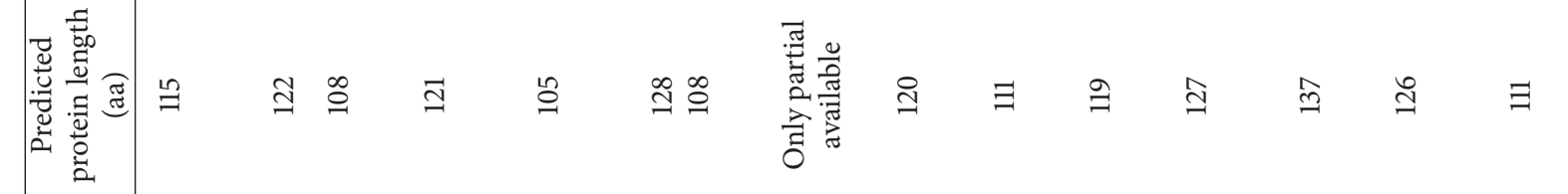
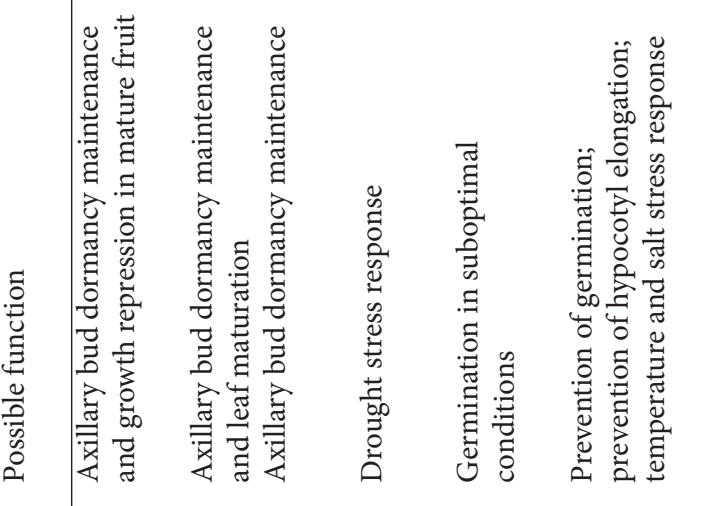

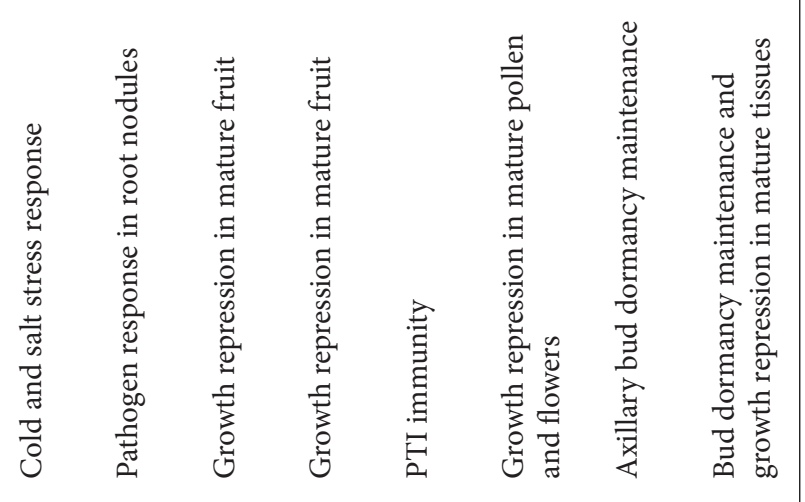

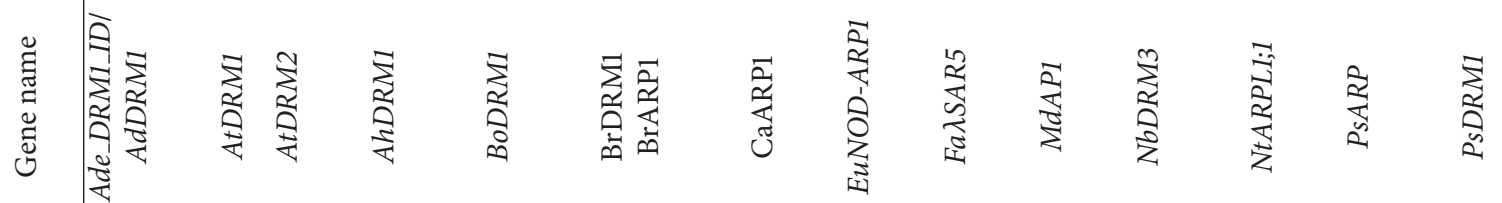

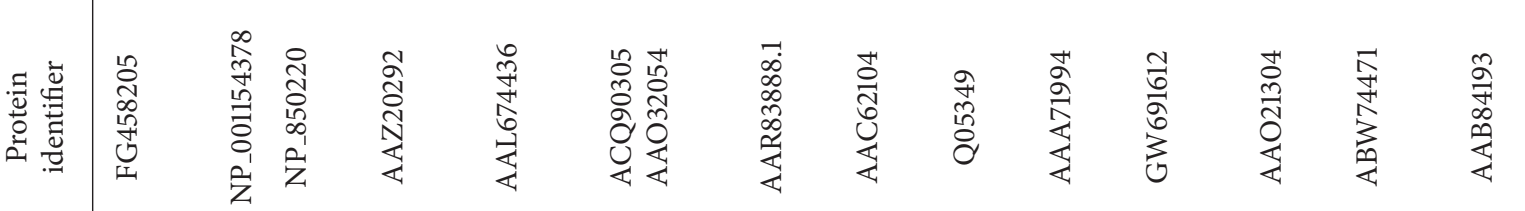

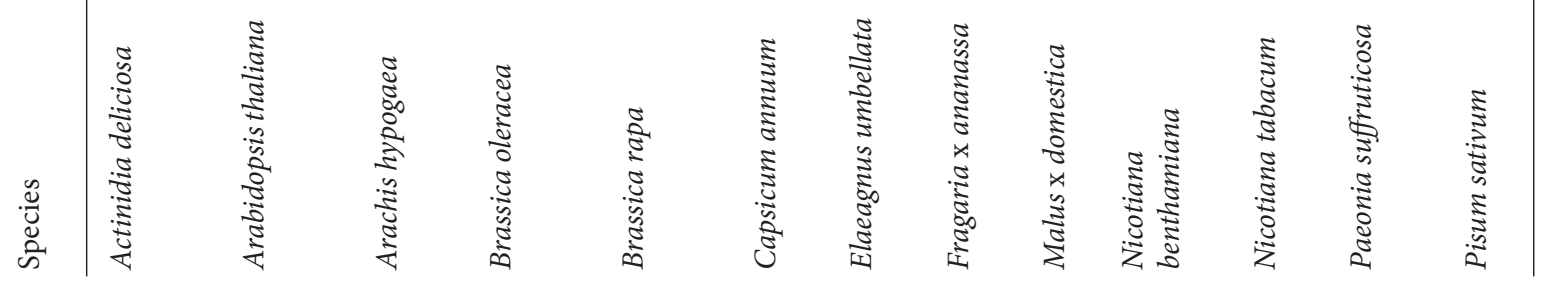




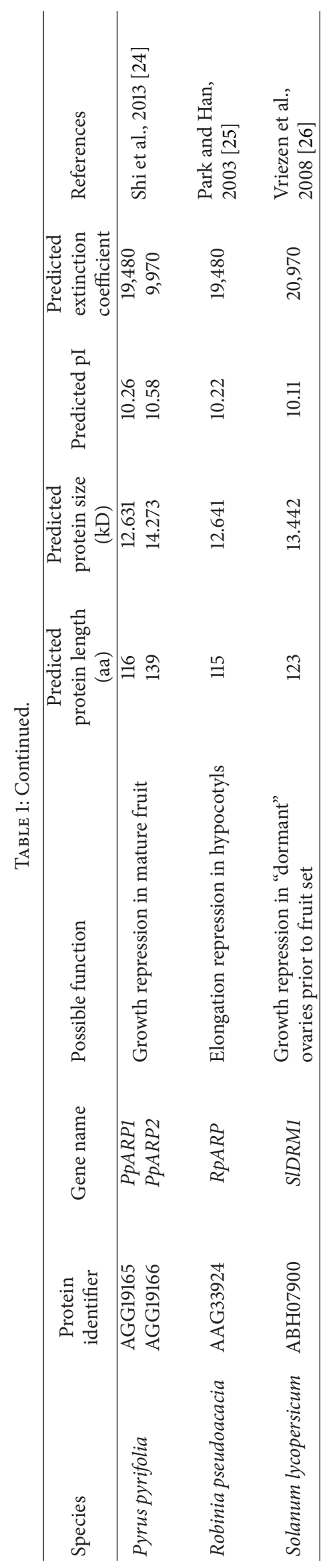


TABLE 2: Transcript expression profiles of $D R M 1 / A R P$ family members in characterised mutants.

\begin{tabular}{|c|c|c|c|c|c|}
\hline Species & Mutant & Mutant phenotype & $\begin{array}{c}\text { Transcript } \\
\text { expression profile } \\
\text { in mutant } c f . \mathrm{WT}\end{array}$ & $\begin{array}{l}\text { Correlation between DRM1/ARP } \\
\text { expression and reduced } \\
\text { branching/enhanced dormancy? }\end{array}$ & Reference \\
\hline Arabidopsis thaliana & phyb & $\begin{array}{l}\text { Reduced branching, } \\
\text { hyperelongation }\end{array}$ & $\uparrow$ & $\mathrm{y}$ & $\begin{array}{l}\text { Finlayson et al., } \\
2010[10]\end{array}$ \\
\hline Arabidopsis thaliana & $t b l 1 / b r c 1$ & Highly branched mutant & - & $\mathrm{n}$ & $\begin{array}{l}\text { Finlayson, } \\
2007[13]\end{array}$ \\
\hline Arabidopsis thaliana & axr1-12 & Highly branched mutant & $\downarrow$ (buds) & $\mathrm{y}$ & $\begin{array}{l}\text { Finlayson, } \\
2007[13]\end{array}$ \\
\hline Arabidopsis thaliana & $\max 2$ & Highly branched mutant & $\downarrow$ (buds) & $\mathrm{y}$ & $\begin{array}{l}\text { Finlayson, } \\
2007[13]\end{array}$ \\
\hline Arabidopsis thaliana & 35S:YUCCA & Reduced branching & - & $\mathrm{n}$ & $\begin{array}{l}\text { Finlayson, } \\
2007[13]\end{array}$ \\
\hline $\begin{array}{l}\text { Wheat } \\
\text { (Triticum aestivum) }\end{array}$ & tin & $\begin{array}{l}\text { Reduced } \\
\text { tillering/branching }\end{array}$ & $\uparrow$ & $\mathrm{y}$ & $\begin{array}{l}\text { Kebrom et al., } \\
2012[11]\end{array}$ \\
\hline $\begin{array}{l}\text { Sorghum } \\
\text { (Sorghum bicolor) }\end{array}$ & phyb-1 & Reduced branching & $\uparrow$ & $\mathrm{y}$ & $\begin{array}{l}\text { Kebrom et al., } \\
2006[27] ; \\
\text { Kebrom et al., } \\
2010[28]\end{array}$ \\
\hline Arabidopsis thaliana & chr12 & $\begin{array}{l}\text { Reduced growth arrest } \\
\text { when exposed to moderate } \\
\text { stress }\end{array}$ & $\downarrow$ & Y & $\begin{array}{l}\text { Mlynárová et al., } \\
2007 \text { [12] }\end{array}$ \\
\hline Arabidopsis thaliana & CHR12 OX & $\begin{array}{l}\text { Growth arrest of normally } \\
\text { active primary buds, and } \\
\text { reduced growth of primary } \\
\text { shoot, only upon } \\
\text { perception of stress } \\
\text { conditions }\end{array}$ & $\uparrow$ & Y & $\begin{array}{l}\text { Mlynárová et al., } \\
2007 \text { [12] }\end{array}$ \\
\hline
\end{tabular}

prediction shows AtDRM1 in the nucleus and mitochondria, possibly suggesting differing roles for family members from different species. No characterised localisation signals or DNA-binding domains are found in the protein sequence. Additionally, the PFAM motif (PF05564), "dormancy-/auxinassociated protein," represents almost the entire protein, leaving few hints on the role of this protein in planta.

Recently evidence has emerged for DRM1/ARP family members as intrinsically disordered proteins (IDPs) [7]. IDPs, found in plants and animals, have a large proportion of their sequence yielding no fixed tertiary structure, yet still providing some biological function [29]. Signal transduction and transcriptional regulation are key processes within which structural disorder is prominent [30, 31]. A well-characterised example of IDPs in the plant kingdom is the late embryogenesis abundant (LEA) class of proteins, involved in abiotic stress tolerance $[32,33]$ as chaperones for other stress response genes [34-36]. ERD10 and ERD14 (early response to dehydration) are members of the dehydrin type of LEA proteins, shown to be both intrinsically disordered and responding to high salinity, drought, and low temperature stresses in Arabidopsis [36]. Similarly, a (LEA)-like phosphoprotein (CDeT11-24) whose expression is associated with periods of dessication has been identified in the resurrection plant Craterostigma plantagineum [37]. Indeed with these findings in mind, DRM1/ARP family members may have roles in chaperoning proteins critical to the no-growth phase in tissues.

Despite the high degree of conservation across species, the biological significance of the DRM1/ARP protein family remains unknown.

\section{Potential Role of $D R M 1 / A R P$ in the Growth/No-Growth Decision outside of Meristematic Tissues}

Despite being a commonly used marker for dormancy, $D R M 1 / A R P$ is expressed in tissues other than dormant axillary buds with high expression often localised to nongrowing tissues. 
Fruit development is an example of the growth/nogrowth homeostasis in floral tissues (cf. vegetative tissues) and as such provides further evidence of DRMI/ARP's association with nongrowing tissues. For example, one DRM1/ARP homologue, AP1, was first discovered in cortical tissue from ripe apple fruit [20]. In addition, Reddy and Poovaiah [19] showed a positive correlation between strawberry (Fragaria ananassa) fruit growth and repression of a homologue identified from a library of fruit starved for auxin, $\lambda S A R 5$, while being highly expressed in mature fruit which have stopped growing. More recently, Pyrus pyrifolia ARP1 (PpARP1) and $P P A R P 2$ expression was detected in the mesocarp tissue of Pear (Pyrus pyrifolia) fruit [24].

Similar data has been seen in kiwifruit with AdDRM1 levels reaching a peak in ripe, mature fruit (unpublished: $M$. Wood), and in tomato where high levels of the gene transcript were localised to the ovaries, with a decrease exhibited after fruit set [26]. It is hypothesised that unpollinated ovaries are in a temporally dormant state, supported by expression of cell cycle genes induced after fruit set [26]. As these tissues may have included seeds and in silico expression profiles show seeds have high levels of SIDRM1 expression, further analysis is required in these species to clarify whether this increase in expression is a result of increases in the maturing fruit flesh or rather in the associated maturing seeds.

Increased $D R M 1 / A R P$ gene expression has also been described in tobacco flowers [22]; mature stems, leaves, and roots of pea [5]; dehisced pollen of tobacco [22]; and root nodules of E. umbellata [18]. While not at particular high levels, DRM1ARP transcript has also been detected in petioles, seeds, various floral organs, and across trunk wood of mature trees $[5,20,22,25,38]$.

A classical example of tissue aging and transitioning into growth suppression is provided in the leaf senescence process. Arabidopsis max 2 mutants, already described earlier for their hyperbranching phenotype, also exhibit increased longevity during leaf senescence [39]. In Arabidopsis, MAX2 transcript expression peaks during the early stages of senescence, while AtDRM1 expression continually increases throughout senescence, reaching a maximum when yellowing begins, at which point expression remained reasonably constant [40]. These data suggest that $D R M 1 / A R P$ is involved in leaf senescence, but later in the process than $M A X 2$, raising the question; is $M A X 2$ controlling DRM1/ARP?

An interesting hypothesis given by Park and Han [25] is for a putative in planta role for DRM1/ARP family members in repression of cell elongation. The authors introduced an inverse correlation between expression of the DRM1/ARP homologue in black locust, RpARP (Robinia pseudoacacia auxin-repressed protein) and the elongation zone of 7-dayold hypocotyls. Possible contradictory evidence is found in the hyperelongated $p h y b$ mutant which has increased DRM1 transcript expression in Arabidopsis axillary buds [10]. To clarify this, AtDRM1 transcript expression would need to be measured in the hyperelongating hypocotyl tissue of the phyb mutant.

PsAD2, another gene identified as being associated with periods of dormancy, showed similar expression profiles outside of purely dormant meristematic tissues (accumulated in axillary buds, roots, mature leaflets, and elongated stems) [41].

\section{DRM1/ARP and Seed Dormancy}

While characteristics of seed dormancy are not generally linked with bud dormancy, some striking similarities do exist. Seed dormancy is defined as the failure of a seed to germinate despite favourable conditions [42, 43]. Some chilling is often required for either seed germination or bud break, in perennial species at least. However, dormancy requires longterm exposure to low temperatures, while stratification of seeds is relatively short term [44]. Microarray expression data show that in Arabidopsis, high levels of AtDRM1 transcript significantly reduce with imbibition [45], while transgenic Arabidopsis lines overexpressing BrDRM1 or BrARP1 exhibited delayed germination phenotypes, providing evidence that DRM1/ARP family members might be involved in seed dormancy maintenance. Assessment of relative DRM1/ARP levels in a seed germination microarray of barley showed that DRM1 was unaffected [46].

Osmopriming of seeds is a process which initiates germination-related processes but does not allow radicle protrusion due the high osmolarity solutions used, limiting water availability. A study completed on Brassica oleracea, comparing the transcriptome of osmoprimed seeds with that of water germinated seeds, identified that DRM1/ARP was expressed in seeds germinated on water and not the osmoprimed seeds [15]. This finding conflicts with the reduction in transcript with imbibition seen in closely related Arabidopsis [45], suggesting that DRM1/ARP's expression levels throughout germination are not integral to the process but might be indirectly linked. This profile in B. oleracea was shared with a number of stress-associated genes, including cyclophilin, superoxide dismutase, GRP2, and glutathione-Stransferase [15], providing evidence that DRM1/ARP might be playing a more general role in stress response in the seed.

\section{Regulation of $D R M 1 / A R P$ Family Gene Expression}

Regulation of DRM1/ARP has been assessed in response to a number of treatments: hormonal, sugars, and abiotic and biotic across a number of plant species.

6.1. Hormonal Regulation of DRM1/ARP. As with many plant genes, $D R M 1 / A R P$ is regulated hormonally. In particular, a number of often conflicting lines of evidence exist suggesting that $D R M 1 / A R P$ family members are regulated by auxin, hence many family members being named ARPs (auxinrepressed proteins).

In 1990, a clone named $\lambda S A R 5$ was identified from cDNA library of strawberry (Fragaria ananassa) fruit starved for auxin [19] and was later found to be a homologue of DRM1/ $A R P$. Strawberry receptacles (the red-fleshed, seed/achenecoated organ) were used as a model for auxin action as the achenes are a source of auxin which controls the receptacle growth in a pollination-dependent manner. Receptacles can be de-achened and then auxin applied exogenously mimicking normal fruit development. 
Within $6 \mathrm{~h}$ from the start of auxin treatment, $\lambda S A R 5$ mRNA levels were significantly lower than those of receptacles with no auxin, suggesting that high levels of auxin may have a role in the downregulation of the DRM1/ARP gene. Repression was not shown with a weak acid control suggesting that any regulatory effects were not simply a result of auxin acid effect. The auxin analogue selected for these experiments was the synthetic naphthalene acetic acid (NAA), as opposed to the naturally occurring indole-3-acetic acid (IAA) for example. NAA can induce stronger effects than IAA due in part to being metabolised more slowly in the plant [47]; therefore any discrepancies observed between NAA and IAA may be a consequence of the nature of the two compounds, although this remains to be determined. Furthermore, NAA was applied at $1 \mathrm{mM}$, significantly greater than an accepted biologically relevant pmol gram $^{-1}$ fresh weight concentrations as determined in Arabidopsis and tobacco [48]. Pollinated fruit which have an endogenous source of auxin from the resulting achenes provide a more biologically relevant assessment of $\lambda S A R 5$ mRNA levels in response to auxin. As expected, $\lambda S A R 5 \mathrm{mRNA}$ levels are higher at 3 and 5 days after pollination (with auxin) than the unpollinated equivalents (no auxin), allowing the conclusion to be drawn that $\lambda S A R 5$ is repressed during normal development of strawberry fruit in response to exogenous auxin. It is noteworthy that the process of de-achening, which was integral to this approach, would likely have induced a number of stress response pathways not specific to the exogenously applied auxin, which may have had separate effects on DRM1/ARP transcription.

A further auxin-repressed homologue from black locust, $R p A R P$, was identified from an EST database of trunk wood from 10-year-old tree, with gene expression seen across all sections of the trunk wood [25]. RpARP levels decrease upon application of exogenous auxin in concentrations as low as $0.1 \mu \mathrm{M}$. Upon removal of the source of auxin, RpARP levels increased again, showing a negative relationship between $D R M 1 / A R P$ family member expression and auxin treatment. Unfortunately, this study also used the synthetic auxin isomer NAA and most of the experiments were completed with $1 \mathrm{mM}$ auxin, beyond the accepted biologically relevant concentration.

Analysis of the roles of noncoding sequences showed that regulatory sequences for auxin repression were located in the UTR sequence as opposed to the promoter sequence for RpARP in transgenic Arabidopsis plants, supporting a possible posttranscriptional regulatory mechanism [25]. This regulation, however, is not mediated by the characterised mRNA instability sequences including cis-elements such as the small auxin upregulated transcript (SAUR) sequences found in the $3^{\prime}$ UTR of several plant genes [49] or the mammalian AU-rich elements (AREs) [25, 50]. The data suggest a novel regulation mechanism that warrants further validation.

While RPARP and indeed $\lambda S A R 5$ are showing some evidence for downregulation in their transcript levels in response to auxin, the timeframe in which this happens can provide insight into whether or not they are likely to be responding directly or indirectly to auxin. Gene expression of primary auxin response genes occurs within a matter of minutes [51-54]. Those genes whose regulation by auxin takes longer than this are generally referred to as secondary auxin responders and are likely to be further downstream in the signalling cascade.

In contrast, analysis carried out in E. umbellata showed that transcript levels in field-grown leaves of a clone identified from a root nodule cDNA library, EuNOD-ARP1,

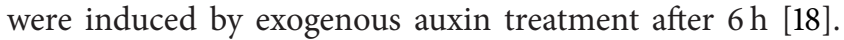
Furthermore, pear mesocarp discs exhibited an increase in transcript expression of $P p A R P 1$ and $P p A R P 2$ with IAA treatment [24]. These pieces of data contradict previous findings in strawberry [19], black locust [25], and in pea [23]. The type and age of the tissue assessed are a major difference between these studies which might explain these variations in auxin response.

A further conflicting finding has been described in Arabidopsis, where auxin overproducing 35S:YUCCA Arabidopsis lines displayed no change in AtDRM1 expression compared to wild-type plants (Table 2) [13]. These mutants showed a reduced branching phenotype and approximately twice the amount of free auxin compared with WT plants [55]. As such Finlayson [13] argued that DRM1/ARP is unlikely to be affected directly by auxin, if at all.

More recently, transgenic Arabidopsis lines overexpressing the coding region of $B r D R M 1$ and $B r A R P 1$, which exhibit reduced hypocotyl growth in dark-grown seedlings, showed a compounded growth suppression with NAA application [16]. That these constructs used the coding region only and therefore do not contain any UTR sequence which would be required for an auxin response based on the Robinia pseudoacacia data [25] suggests that any auxin responses in this gene family might be regulated by different mechanisms in different species.

Overall these data question whether or not DRM1/ARP family members are regulated by auxin with conflicting data emerging from various experimental setups. Thorough analyses of auxin regulation in planta with a focus on biological relevance are therefore required.

Only scarce data are available pertaining to the effects of hormones other than auxin on expression of DRM1/ARP family members. In pea it was shown that PsDRM1 is induced when samples were treated with ABA [23], while GA had no effect on transcript levels. Despite being the sole piece of published data on $A B A$ regulation of $D R M 1 / A R P$, the gene has been used as a genetic marker for ABA response in studies of fruit set in tomato [26]. Vriezen et al. [26] argue that the decrease in DRM1/ARP after fruit set might be due to lower levels of ABA in the ovary after induction of fruit growth, although this remains to be assessed further.

Few data are available on any response of DRM1/ARP family members to cytokinin treatment; however, it would be expected that cytokinin treatment, which is generally associated with an increase in cell division, would lead to a decrease in transcript levels of DRM1/ARP. The only data available are from a transcriptomic approach comparing Arabidopsis seedlings treated with BAP with nontreated plants. A decrease in both AtDRM1 and AtDRM2 levels was observed 
but further validation of this finding remains to be completed [56].

6.2. Regulation of DRM1/ARP Family Members by Sugars. A plant needs carbohydrates in the form of sugars to grow. In particular, sugar is required for expression of the cell cycle gene CyclinD3 [57, 58]. Similarly, carbohydrate metabolism genes have been shown to change over the three distinct phases of dormancy in the buds of the perennial weed, leafy spurge [59], making a clear link between sugar levels and ratios to dormancy.

An association between sugar and DRM1/ARP was first described in black locust in 2003 [25]. In an attempt to further understand auxin regulation of $R p A R P$, sucrose was analysed as a factor associated with auxin-mediated growth. Sugar deprivation led to an increase in $R p A R P$ gene expression. As discussed above in this paper's findings on auxin regulation, the age of this tissue, and therefore whether or not it was growing, was not mentioned in the text and age of the tissue may have an impact on the findings. Upon discovery of the sugar response, the upstream promoter sequence was screened and four sugar responsive elements (SREs), known to be responsible for sugar repression of the $\alpha$-amylase gene in rice [60], were identified [61]. Furthermore, it was shown that the promoter sequence was required to mediate the sugar response [25].

A subsequent, in-depth study of sugar regulation of $D R M 1 / A R P$, amongst other genes, was carried out by Gonzali et al. [62]. In support of the findings of Park and Han [25], they described almost a complete repression of AtDRM1 by sucrose, fructose, and glucose, but not by other sugars including turanose and mannitol. As modulation of AtDRM1 was seen as a result of more than one sugar type, it was concluded that AtDRM1 could be a low-specificity sensor of sugars [62].

More recently, studies of the reduced branching tin (tiller inhibition) mutant in wheat (Triticum aestivum) have drawn a link between sugar levels, dormancy status, and DRM1/ARP [11]. The dormant buds of tin show reduced sucrose content, transcriptional responses in both sucrose-inducible and sucrose starvation-inducible markers (downregulation and upregulation, resp.) and reduction in transcript expression of cell cycle markers leading to the hypothesis that the extensive bud dormancy seen in the mutant is due to cessation of cell division due to diversion of sucrose away from the buds. The dormancy status of the buds of tin plants was confirmed by DRM1/ARP and TBL1 transcript expression assessment leading to an additional hypothesis that $D R M 1 / A R P$ (as well as TBL1) are involved in dormancy responses specifically related to sucrose starvation [11]. Data from kiwifruit have shown that sucrose levels accumulate in dormant buds over winter and reduce again prior to bud break in spring [63]. Indeed, application of hydrogen cyanamide is associated with a rapid decrease in both detectable sucrose levels [63] and $D R M 1 / A R P$ transcript levels [7].

Work in Arabidopsis showed a somewhat contradictory result [6]. A microarray was carried out allowing categorisation of genes categorised as either up- or downregulated in response to inflorescence decapitation. Both AtDRM1 and AtDRM2 were downregulated in buds upon decapitation [6]. A search for regulatory elements enriched in promoter sequences of either group identified Sugar Responsive Elements (SREs) as being highly conserved in genes downregulated with decapitation. It must be noted, however, that this work only analysed the initial $500 \mathrm{bp}$ upstream of the start codon and as such possibly neglected the majority of the promoter sequences. Furthermore, these motifs remain to be assessed biologically, which will inevitably provide a more robust basis for any hypotheses. These conflicting pieces of data suggest that $D R M 1 / A R P$ family members are unlikely to be directly regulated by sugar levels.

6.3. Regulation of DRM1/ARP Family Members by Abiotic and Biotic Stresses. Across the plant kingdom, DRM1/ARP is increasingly being linked to stress responses, whether they are a result of abiotic or biotic factors.

Increases in DRM1/ARP transcript levels have been associated with the light signalling pathway mutant, phyb, in both Arabidopsis and Sorghum (Sorghum bicolor) [10, 27, 28] (Table 2). phyb mutants have reduced bud outgrowth, with a concomitant increase in DRM1 expression $[10,27$, 28], providing support for the hypothesis that $D R M 1 / A R P$ is involved in growth suppression in bud and hypocotyls tissues.

Other abiotic stress factors have also been considered. An increase in DRM1/ARP expression with cold treatment or salt stress has been documented in pea [23], Capsicum annuum [17], and the close relative of Arabidopsis, B. rapa [16]. During times of eco-dormancy due to cold, it might be anticipated that $D R M 1 / A R P$ expression is high, suggesting a role for $D R M 1 / A R P$ in temperature signalling. An interesting set of experiments considered the effect of various growth regulators and abiotic stresses in conjunction with auxin application on $R P A R P$ gene expression [25]. Data showed that $R P A R P$ expression was induced either with or without auxin by cold stress providing evidence for cold stress overriding any auxin response. Other treatments showed no significant effect on transcript profiles. These data provide further evidence for DRM1/ARP family members not being directly regulated by auxin.

$D R M 1 / A R P$ transcript expression has been assessed in response to further abiotic factors including drought conditions in peanut (Arachis hypogaea) [14] and heat shock in B. rapa [16], with both conditions leading to an increase in expression.

AtDRM1 and AtDRM2 levels are increased in the SNF2/ Brahma-type AtCHR12 chromatin-remodelling gene overexpression lines, introduced earlier, which undergo arrest of axillary bud outgrowth and a reduction in inflorescence bolt growth, only in response to stress conditions [12]. Conversely, transcript levels of AtDRM1 and AtDRM2 are downregulated in Atchr12 knock-out mutants [12]. These findings suggest that AtDRM1/ARP genes might be acting downstream of AtCHR12 in a stress-modulated pathway.

As well as being involved in responses to abiotic factors, DRM1/ARP family members have also been linked to biotic stress responses. A cell death-based assay was undertaken using transient virus-induced gene silencing of DRM3 (homologue of a closely related DRM family member 


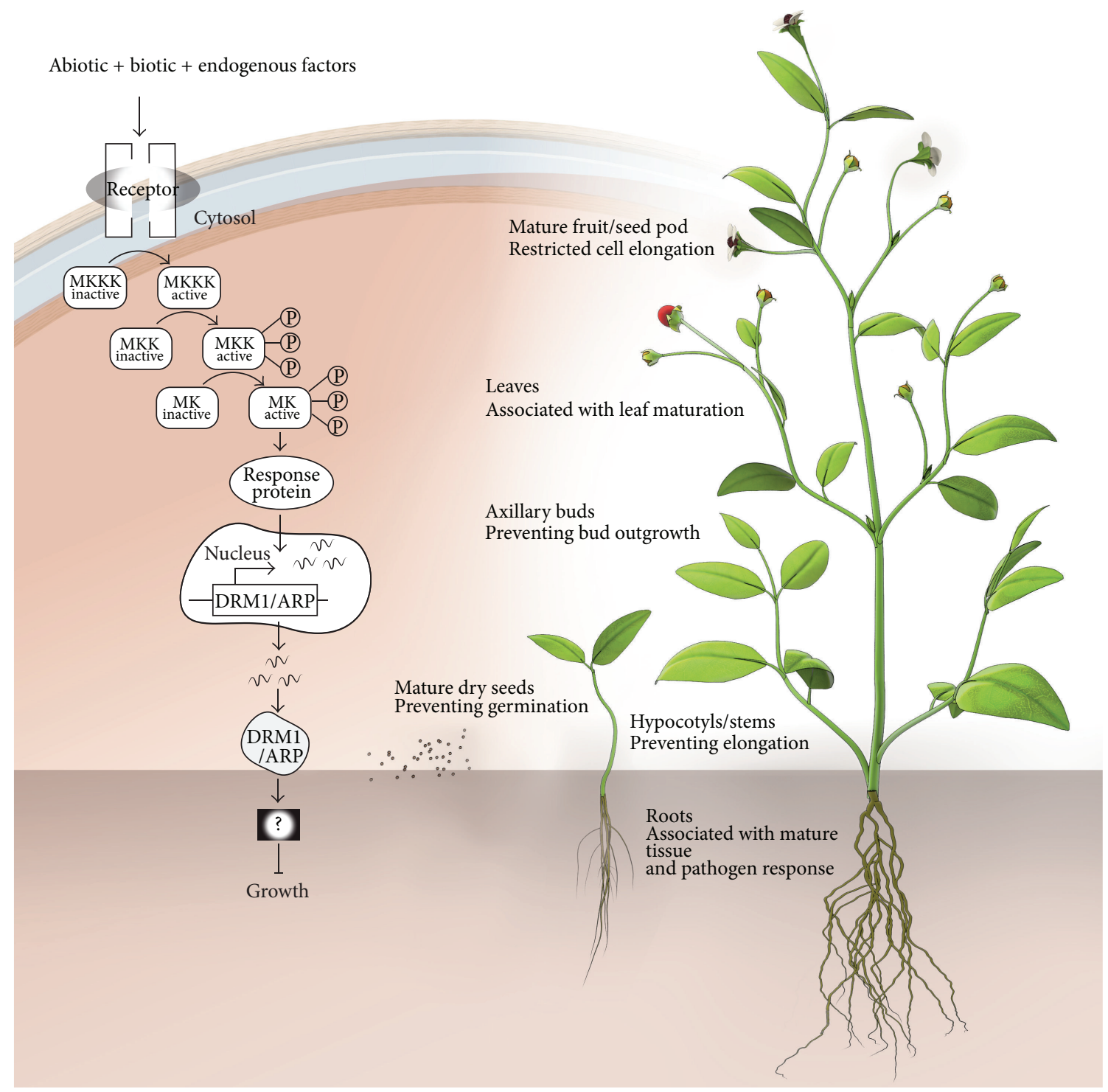

FIGURE 2: Schematic diagram of hypothetical in planta functions of DRM1/ARP. Mitogen activated protein (MAP) kinase, kinase, kinase (MKKK), MAP kinase, kinase (MKK), and MAP kinase (MK) are representative of a generalised signalling cascade resulting in expression of $D R M 1 / A R P$ 's, in response to a range of abiotic, biotic, and endogenous factors. DRM1/ARP proteins are hypothesised to play a role in growth inhibition via a currently unknown pathway.

At1g56220) in Nicotiana benthamiana. Plants silenced for NbDRM3 and challenged with a number of bacterial effectors were compromised in their pathogen-associated molecular pattern-triggered immunity (PTI) [21].

These data combined with the fact that DRM1/ARP proteins in kiwifruit have been shown to be IDPs [7], a class of proteins often associated with stress response pathways in plants, as well as multiple lines of evidence showing transcript expression outside of purely dormant tissue provide increasing evidence that DRM1/ARPs are involved in responding to suboptimal conditions, whether they be abiotic or biotic, and whether this is in meristematic tissue with (by definition) the potential to go dormant or not.

\section{DRM1/ARP Mutants}

Analysis of plant lines either overexpressing a gene and its resulting protein or downregulating expression is a powerful tool for characterizing a gene's role in planta.

Studies conducted in black locust [25] stated that overexpression of full length $R p A R P$ cDNA either with or without the UTRs resulted in Arabidopsis plants with no change in phenotype compared with wild-type plants. Similarly, overexpression of EuNOD-ARP1 cDNA in Arabidopsis had no noticeable phenotype [18].

More recently, data have emerged claiming a number of alterations to the visible phenotype of Arabidopsis plants 
overexpressing cDNA of either of two homologues of DRM1 and $A R P 1$ from $B$. rapa. These included a reduction in vegetative growth (petiole length), as well as a reduction in seed productivity (silique length). A general delay in growth with no significant impact on bolting times was also reported, resulting in a reduction in the number of leaves associated with the vegetative-floral phase transition. In addition, transgenic plants exhibited a reduction in bolt length and a delay in seed germination. Double knockouts to AtDRM1 and AtDRM2 exhibited no change in phenotype [16]. These findings are of particular interest as they conflict with other species assessed thus far, providing further evidence of differing roles of $D R M 1 / A R P$ family members across different plant species.

\section{Conclusions and Future Directions}

As highlighted in this review, DRM1/ARP transcript expression has generally been associated with dormant buds. Exceptions to this association are seen in tbl1/brcl and 35S:YUCCA mutants, suggesting that $D R M 1 / A R P$ is not playing a specific role in dormancy maintenance and as such may not be a reliable maker for dormancy release in future studies. Furthermore, the detection of transcripts outside of meristematic tissues, by definition the site of dormancy, often in nongrowing tissue means that the correlation between DRM1/ARP and dormant tissues is more likely representative of a link between the nongrowth status of these tissues, as opposed to dormancy per se (Figure 2).

This plant-specific gene and its resulting low molecular weight protein are highly conserved, and it may be negatively regulated by auxin. Ever since the identification of the dormancy-associated gene $D R M 1 / A R P$ in pea more than a decade ago, and more recently in other species, its mode of action has still to be elucidated. Future work will require a multifaceted approach in order to draw conclusions on the function of DRM1/ARP in planta. Due to the conflicting findings around $D R M 1 / A R P$ mutants, further analysis on a number of species is required to clarify the effect that either overexpression or downregulation of DRM1/ARP genes has on the plant. Transcriptome analysis of these various mutants will provide further information on the function of DRM1/ARP. Further physiological and transcriptional studies considering additional abiotic and biotic stress factors, as well as those already described in more depth, will be of interest. Antibodies would be helpful to use for protein localisation studies which could complement promoter: GUS analysis looking into the means of transcriptional regulation of this gene family. Finally, protein-protein interaction experiments, such as yeast-2-hybrid assays, could allow elucidation of binding partners.

Through identification of genetic pathways the genes are involved in; identification of the regulatory mechanisms of the genes; localisation studies at the protein level; and identification of binding partners, the function of $D R M 1 / A R P$ will be clarified.

\section{Conflict of Interests}

No conflict of interests exists for any of the authors in relation to the work discussed in this paper.

\section{Acknowledgments}

Thanks are due to Minna Pesonen and David Moore for the development of graphic images (Figures 1 and 2, resp.).

\section{References}

[1] G. A. Lang, J. D. Early, G. C. Martin, and R. L. Darnell, "Endo-, para-, and ecodormancy: physiological terminology and classification for dormancy research," HortScience, vol. 22, no. 3, pp. 371-377, 1987.

[2] K. V. Thimann and F. Skoog, "On the inhibition of bud development and other functions of growth substances in Vicia faba," Proceedings of the Royal Society of London, vol. 114, no. 789, pp. 317-339, 1934.

[3] M. A. Domagalska and O. Leyser, "Signal integration in the control of shoot branching," Nature Reviews Molecular Cell Biology, vol. 12, no. 4, pp. 211-221, 2011.

[4] Y. Seto, H. Kameoka, S. Yamaguchi, and J. Kyozuka, "Recent advances in strigolactone research: chemical and biological aspects," Plant and Cell Physiology, vol. 53, no. 11, pp. 1843-1853, 2012.

[5] J. P. Stafstrom, B. D. Ripley, M. L. Devitt, and B. Drake, "Dormancy-associated gene expression in pea axillary buds. Cloning and expression of PsDRM1 and PsDRM2," Planta, vol. 205, no. 4, pp. 547-552, 1998.

[6] K. Tatematsu, S. Ward, O. Leyser, Y. Kamiya, and E. Nambara, "Identification of cis-elements that regulate gene expression during initiation of axillary bud outgrowth in Arabidopsis," Plant Physiology, vol. 138, no. 2, pp. 757-766, 2005.

[7] M. Wood, G. M. Rae, R.-M. Wu et al., "Actinidia DRM1an intrinsically disordered protein whose mRNA expression is inversely correlated with spring budbreak in kiwifruit," PLoS ONE, vol. 8, no. 3, Article ID e57354, 2013.

[8] D. P. Horvath, J. V. Anderson, W. S. Chao, and M. E. Foley, "Knowing when to grow: signals regulating bud dormancy," Trends in Plant Science, vol. 8, no. 11, pp. 534-540, 2003.

[9] X. Huang, T. Xue, S. Dai, S. Gai, C. Zheng, and G. Zheng, "Genes associated with the release of dormant buds in tree peonies (Paeonia suffruticosa)," Acta Physiologiae Plantarum, vol. 30, no. 6, pp. 797-806, 2008.

[10] S. A. Finlayson, S. R. Krishnareddy, T. H. Kebrom, and J. J. Casal, "Phytochrome regulation of branching in Arabidopsis," Plant Physiology, vol. 152, no. 4, pp. 1914-1927, 2010.

[11] T. H. Kebrom, P. M. Chandler, S. M. Swain, R. W. King, R. A. Richards, and W. Spielmeyer, "Inhibition of tiller bud outgrowth in the tin mutant of wheat is associated with precocious internode development," Plant Physiology, vol. 160, no. 1, pp. 308-318, 2012.

[12] L. Mlynárová, J.-P. Nap, and T. Bisseling, “The SWI/SNF chromatin-remodeling gene AtCHR12 mediates temporary growth arrest in Arabidopsis thaliana upon perceiving environmental stress," The Plant Journal, vol. 51, no. 5, pp. 874-885, 2007.

[13] S. A. Finlayson, “Arabidopsis TEOSINTE BRANCHED1-LIKE 1 regulates axillary bud outgrowth and is homologous to monocot TEOSINTE BRANCHED1," Plant and Cell Physiology, vol. 48, no. 5, pp. 667-677, 2007.

[14] G. Govind, H. Vokkaliga Thammegowda, P. Jayaker Kalaiarasi et al., "Identification and functional validation of a unique set of drought induced genes preferentially expressed in response to gradual water stress in peanut," Molecular Genetics and Genomics, vol. 281, no. 6, pp. 591-605, 2009. 
[15] Y. Soeda, M. C. J. M. Konings, O. Vorst et al., "Gene expression programs during Brassica oleracea seed maturation, osmopriming, and germination are indicators of progression of the germination process and the stress tolerance level," Plant Physiology, vol. 137, no. 1, pp. 354-368, 2005.

[16] J. Lee, C.-T. Han, and Y. Hur, "Molecular characterization of the Brassica rapa auxin-repressed, superfamily genes, BrARP1 and BrDRM1," Molecular Biology Reports, vol. 40, no. 1, pp. 197-209, 2013.

[17] E. W. Hwang, K. A. Kim, S. C. Park, M. J. Jeong, M. O. Byun, and H. B. Kwon, "Expression profiles of hot pepper (Capsicum annuum) genes under cold stress conditions," Journal of Biosciences, vol. 30, no. 5, pp. 657-667, 2005.

[18] H. B. Kim, H. Lee, C. J. Oh, N. H. Lee, and C. S. An, "Expression of EuNOD-ARP1 encoding auxin-repressed protein homolog is upregulated by auxin and localized to the fixation zone in root nodules of Elaeagnus umbellata," Molecules and Cells, vol. 23, no. 1, pp. 115-121, 2007.

[19] A. S. N. Reddy and B. W. Poovaiah, "Molecular cloning and sequencing of a cDNA for an auxin-repressed mRNA: correlation between fruit growth and repression of the auxin-regulated gene," Plant Molecular Biology, vol. 14, no. 2, pp. 127-136, 1990.

[20] S. A. Lee, R. C. Gardner, and M. Lay-Yee, "An apple gene highly expressed in fruit," Plant Physiology, vol. 103, no. 3, p. 1017, 1993.

[21] S. Chakravarthy, A. C. Velásquez, S. K. Ekengren, A. Collmer, and G. B. Martin, "Identification of Nicotiana benthamiana genes involved in pathogen-associated molecular pattern-triggered immunity," Molecular Plant-Microbe Interactions, vol. 23, no. 6, pp. 715-726, 2010.

[22] C. Steiner, J. Bauer, N. Amrhein, and M. Bucher, "Two novel genes are differentially expressed during early germination of the male gametophyte of Nicotiana tabacum," Biochimica et Biophysica Acta, vol. 1625, no. 2, pp. 123-133, 2003.

[23] J. P. Stafstrom, "Regulation of growth and dormancy in pea axillary buds," in Dormancy in Plants, J.-D. Viemont and J. Crabbé, Eds., pp. 331-346, CAB International, Wallingford, UK, 2000.

[24] H.-Y. Shi, Y.-X. Zhang, and L. Chen, "Two pear auxinrepressed protein genes, PpARP1 and PpARP2, are predominantly expressed in fruit and involved in response to salicylic acid signaling," Plant Cell, Tissue and Organ Culture, pp. 1-8, 2013.

[25] S. Park and K. Han, "An auxin-repressed gene (RpARP) from black locust (Robinia pseudoacacia) is posttranscriptionally regulated and negatively associated with shoot elongation," Tree Physiology, vol. 23, no. 12, pp. 815-823, 2003.

[26] W. H. Vriezen, R. Feron, F. Maretto, J. Keijman, and C. Mariani, "Changes in tomato ovary transcriptome demonstrate complex hormonal regulation of fruit set," New Phytologist, vol. 177, no. 1, pp. 60-76, 2008.

[27] T. H. Kebrom, B. L. Burson, and S. A. Finlayson, "Phytochrome B represses Teosinte Branched1 expression and induces sorghum axillary bud outgrowth in response to light signals," Plant Physiology, vol. 140, no. 3, pp. 1109-1117, 2006.

[28] T. H. Kebrom, T. P. Brutnell, and S. A. Finlayson, "Suppression of sorghum axillary bud outgrowth by shade, phyB and defoliation signalling pathways," Plant, Cell and Environment, vol. 33, no. 1, pp. 48-58, 2010.

[29] A. K. Dunker, J. D. Lawson, C. J. Brown et al., "Intrinsically disordered protein," Journal of Molecular Graphics and Modelling, vol. 19, no. 1, pp. 26-59, 2001.
[30] L. M. Iakoucheva, C. J. Brown, J. D. Lawson, Z. Obradović, and A. K. Dunker, "Intrinsic disorder in cell-signaling and cancerassociated proteins," Journal of Molecular Biology, vol. 323, no. 3, pp. 573-584, 2002.

[31] Y. Minezaki, K. Homma, A. R. Kinjo, and K. Nishikawa, "Human transcription factors contain a high fraction of intrinsically disordered regions essential for transcriptional regulation," Journal of Molecular Biology, vol. 359, no. 4, pp. 1137-1149, 2006.

[32] A. Garay-Arroyo, J. M. Colmenero-Flores, A. Garciarrubio, and A. A. Covarrubias, "Highly hydrophilic proteins in prokaryotes and eukaryotes are common during conditions of water deficit," The Journal of Biological Chemistry, vol. 275, no. 8, pp. 5668$5674,2000$.

[33] J. M. Mouillon, P. Gustafsson, and P. Harryson, "Structural investigation of disordered stress proteins. Comparison of fulllength dehydrins with isolated peptides of their conserved segments," Plant Physiology, vol. 141, no. 2, pp. 638-650, 2006.

[34] S. Chakrabortee, C. Boschetti, L. J. Walton, S. Sarkar, D. C. Rubinsztein, and A. Tunnacliffe, "Hydrophilic protein associated with desiccation tolerance exhibits broad protein stabilization function," Proceedings of the National Academy of Sciences of the United States of America, vol. 104, no. 46, pp. 18073-18078, 2007.

[35] D. Kovacs, B. Agoston, and P. Tompa, "Disordered plant LEA proteins as molecular chaperones," Plant Signaling and Behavior, vol. 3, no. 9, pp. 710-713, 2008.

[36] D. Kovacs, E. Kalmar, Z. Torok, and P. Tompa, "Chaperone activity of ERD10 and ERD14, two disordered stress-related plant proteins," Plant Physiology, vol. 147, no. 1, pp. 381-390, 2008.

[37] J. Petersen, S. K. Eriksson, P. Harryson et al., “The lysine-rich motif of intrinsically disordered stress protein CDeT11-24 from Craterostigma plantagineum is responsible for phosphatidic acid binding and protection of enzymes from damaging effects caused by desiccation," Journal of Experimental Botany, vol. 63, no. 13, pp. 4919-4929, 2012.

[38] G. S. Ross, M. L. Knighton, and M. Lay-Yee, "An ethylenerelated cDNA from ripening apples," Plant Molecular Biology, vol. 19, no. 2, pp. 231-238, 1992.

[39] H. R. Woo, K. M. Chung, J. H. Park et al., "ORE9, an F-box protein that regulates leaf senescence in Arabidopsis," Plant Cell, vol. 13, no. 8, pp. 1779-1790, 2001.

[40] E. Breeze, E. Harrison, S. McHattie et al., "High-resolution temporal profiling of transcripts during Arabidopsis leaf senescence reveals a distinct chronology of processes and regulation," Plant Cell, vol. 23, no. 3, pp. 873-894, 2011.

[41] Y. Madoka and H. Mori, "Two novel transcripts expressed in pea dormant axillary buds," Plant and Cell Physiology, vol. 41, no. 3, pp. 274-281, 2000.

[42] J. D. Bewley, "Seed germination and dormancy," Plant Cell, vol. 9, no. 7, pp. 1055-1066, 1997.

[43] G. M. Simpson, Seed Dormancy in Grasses, Cambridge University Press, Cambridge, UK, 1990.

[44] A. Rohde and R. P. Bhalerao, "Plant dormancy in the perennial context," Trends in Plant Science, vol. 12, no. 5, pp. 217-223, 2007.

[45] M. Schmid, T. S. Davison, S. R. Henz et al., "A gene expression map of Arabidopsis thaliana development," Nature Genetics, vol. 37, no. 5, pp. 501-506, 2005.

[46] J. M. Barrero, M. J. Talbot, R. G. White, J. V. Jacobsen, and F. Gubler, "Anatomical and transcriptomic studies of the 
coleorhiza reveal the importance of this tissue in regulating dormancy in Barley," Plant Physiology, vol. 150, no. 2, pp. 10061021, 2009.

[47] E. M. Beyer and P. W. Morgan, "Effect of ethylene on the uptake, distribution, and metabolism of indoleacetic acid-1- ${ }^{14} \mathrm{C}$ and -2${ }^{14} \mathrm{C}$ and naphthaleneacetic acid-1- ${ }^{14} \mathrm{C}$, Plant Physiology, vol. 46, no. 1, pp. 157-162, 1970.

[48] Y. Izumi, A. Okazawa, T. Bamba, A. Kobayashi, and E. Fukusaki, "Development of a method for comprehensive and quantitative analysis of plant hormones by highly sensitive nanoflow liquid chromatography-electrospray ionization-ion trap mass spectrometry," Analytica Chimica Acta, vol. 648, no. 2, pp. 215225, 2009.

[49] P. Gil and P. J. Green, "Multiple regions of the Arabidopsis SAUR$A C 1$ gene control transcript abundance: the $3^{\prime}$ untranslated region functions as an mRNA instability determinant," The EMBO Journal, vol. 15, no. 7, pp. 1678-1686, 1996.

[50] C. Y. A. Chen and A. B. Shyu, "AU-rich elements: characterization and importance in mRNA degradation," Trends in Biochemical Sciences, vol. 20, no. 11, pp. 465-470, 1995.

[51] S. Abel and A. Theologis, "Early genes and auxin action," Plant Physiology, vol. 111, no. 1, pp. 9-17, 1996.

[52] J. L. Key, N. M. Barnett, and C. Y. Lin, "RNA and protein biosynthesis and the regulation of cell elongation by auxin," Annals of the New York Academy of Sciences, vol. 144, no. 1, pp. 49-62, 1967.

[53] A. Theologis, T. V. Huynh, and R. W. Davis, "Rapid induction of specific mRNAs by auxin in pea epicotyl tissue," Journal of Molecular Biology, vol. 183, no. 1, pp. 53-68, 1985.

[54] A. Theologis and P. M. Ray, "Early auxin-regulated polyadenylylated mRNA sequences in pea stem tissue," Proceedings of the National Academy of Sciences of the United States of America, vol. 79, no. 2, pp. 418-421, 1982.

[55] Y. Zhao, S. K. Christensen, C. Fankhauser et al., "A role for flavin monooxygenase-like enzymes in auxin biosynthesis," Science, vol. 291, no. 5502, pp. 306-309, 2001.

[56] D. L. Lindsay, Cytokinin-induced gene expression in Arabidopsis [Degree of doctor of philosophy], Department of Biology, University of Saskatchewan, Saskatoon,Canada, 2006.

[57] J. M. S. Healy, M. Menges, J. H. Doonan, and J. A. H. Murray, "The Arabidopsis D-type cyclins CycD2 and CycD3 both interact in vivo with the PSTAIRE cyclin-dependent kinase Cdc2a but are differentially controlled," The Journal of Biological Chemistry, vol. 276, no. 10, pp. 7041-7047, 2001.

[58] E. A. Oakenfull, C. Riou-Khamlichi, and J. A. H. Murray, "Plant D-type cyclins and the control of G1 progression," Philosophical Transactions of the Royal Society B, vol. 357, no. 1422, pp. 749$760,2002$.

[59] W. S. Chao and M. D. Serpe, "Changes in the expression of carbohydrate metabolism genes during three phases of bud dormancy in leafy spurge," Plant Molecular Biology, vol. 73, no. 1-2, pp. 227-239, 2010.

[60] C. A. Lu, E. K. Lim, and S. M. Yu, "Sugar response sequence in the promoter of a rice $\alpha$-amylase gene serves as a transcriptional enhancer," The Journal of Biological Chemistry, vol. 273, no. 17, pp. 10120-10131, 1998.

[61] E. Nambara, M. Okamoto, K. Tatematsu, R. Yano, M. Seo, and Y. Kamiya, "Abscisic acid and the control of seed dormancy and germination," Seed Science Research, vol. 20, no. 2, pp. 55-67, 2010.

[62] S. Gonzali, E. Loreti, C. Solfanelli, G. Novi, A. Alpi, and P. Perata, "Identification of sugar-modulated genes and evidence for in vivo sugar sensing in Arabidopsis," Journal of Plant Research, vol. 119, no. 2, pp. 115-123, 2006.

[63] A. C. Richardson, E. F. Walton, H. L. Boldingh, and J. S. Meekings, "Seasonal carbohydrate changes in dormant kiwifruit buds," in Proceedings of the 6th International Symposium on Kiwifruit, vol. 753, pp. 567-572, 2007. 

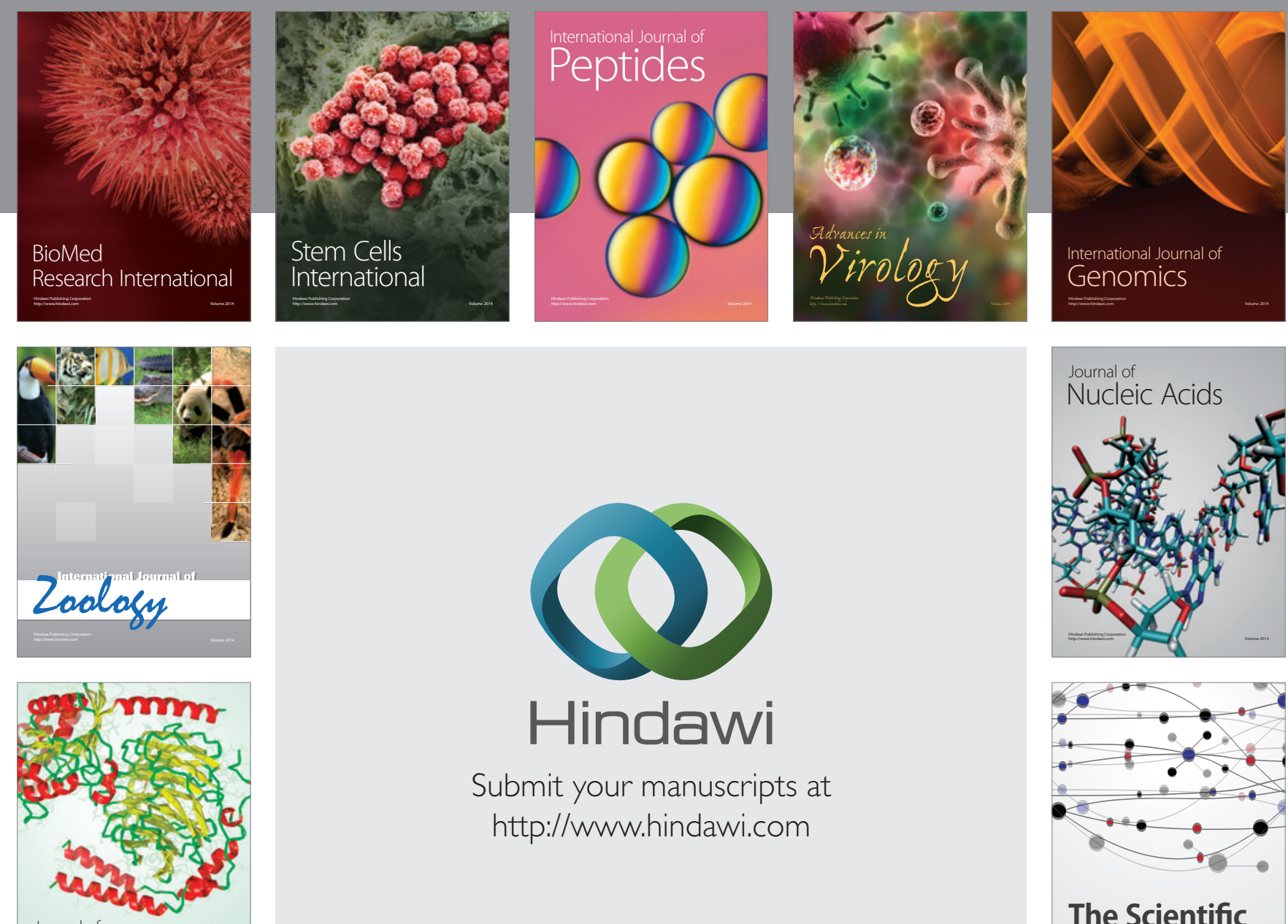

Submit your manuscripts at

http://www.hindawi.com

Journal of
Signal Transduction
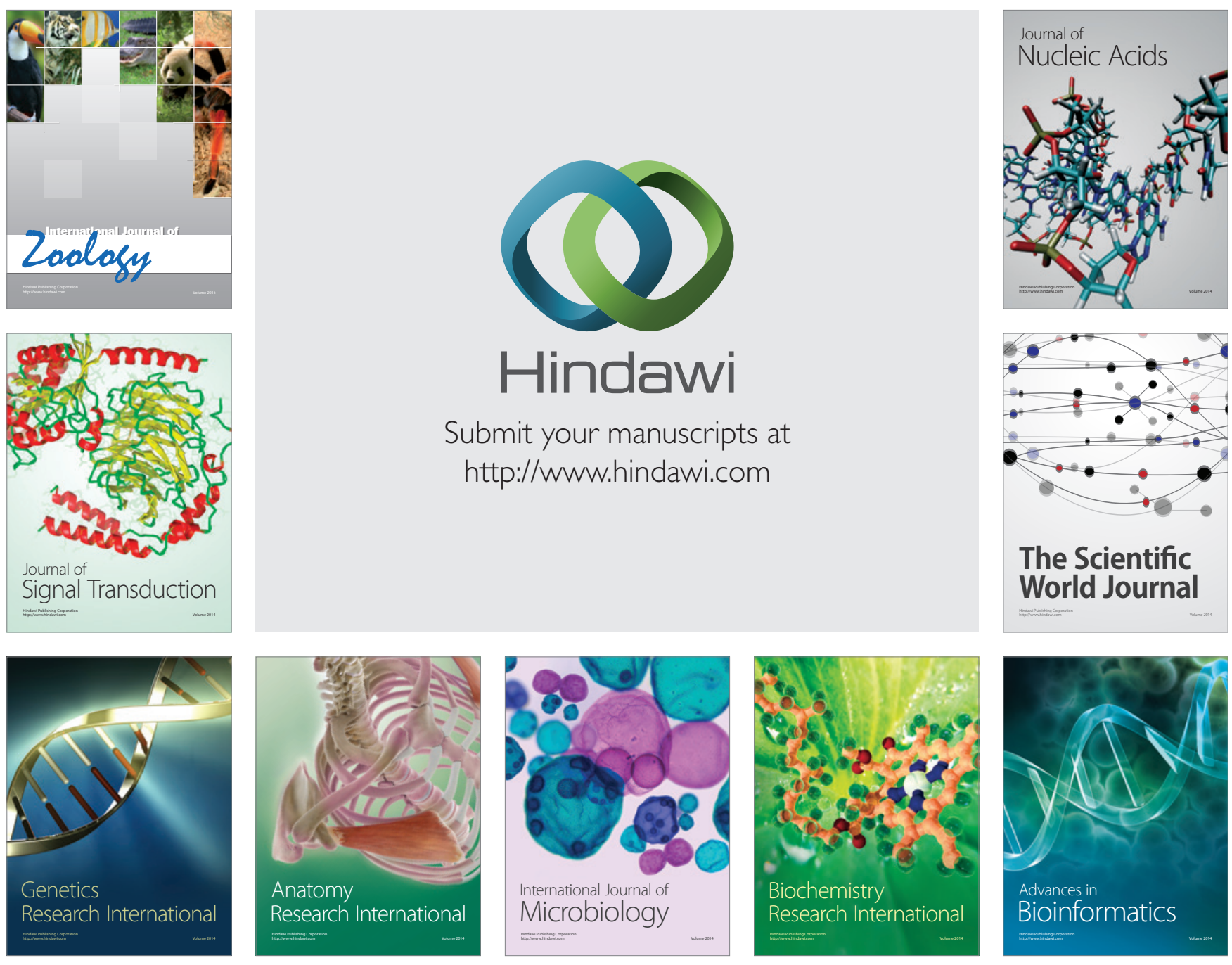

The Scientific World Journal
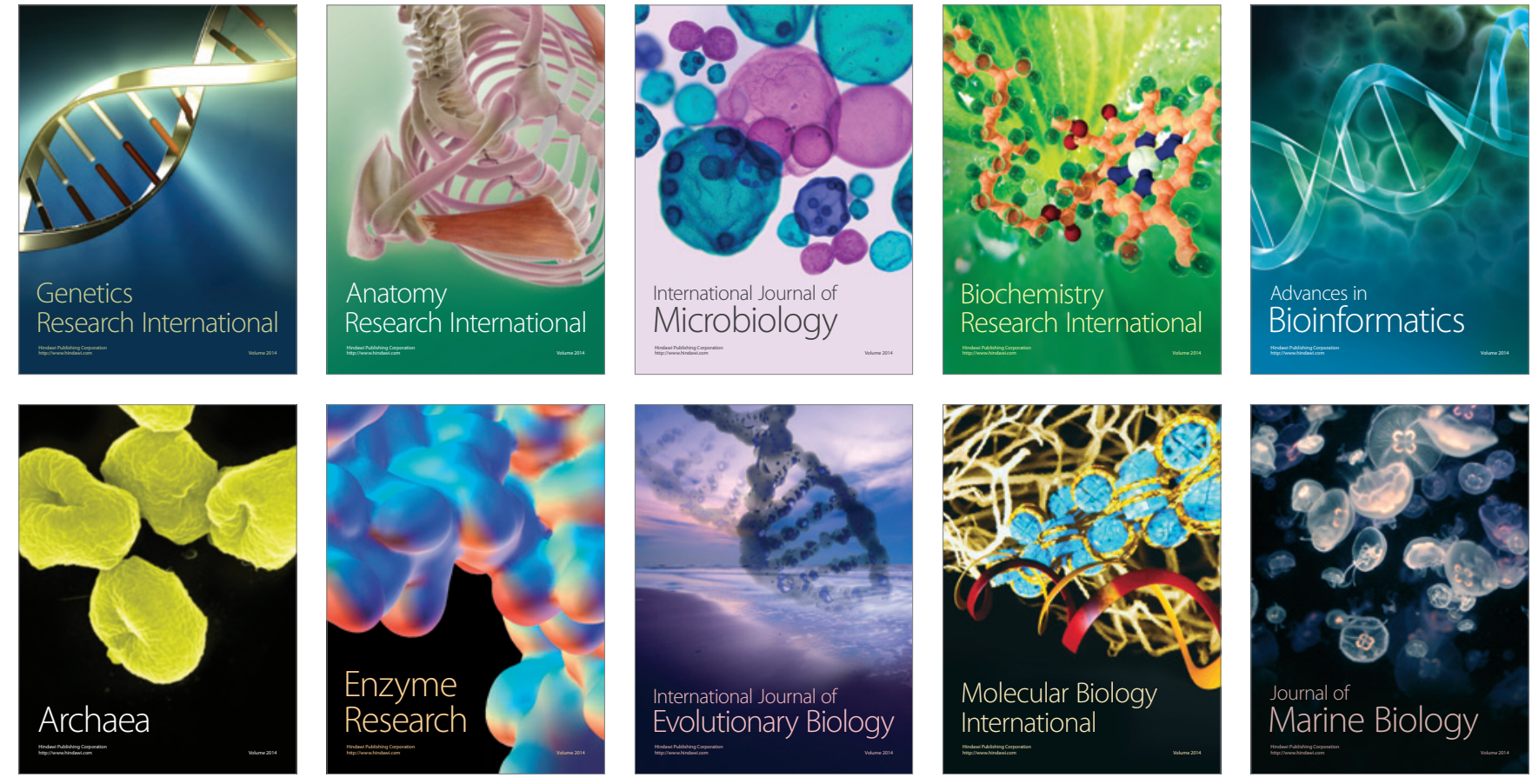